УДК 621.18-182.2

\title{
ТЕСТИРОВАНИЕ ТЕХНИЧЕСКИХ РЕШЕНИЙ ПО ТОПОЧНО-ГОРЕЛОЧНЫМ УСТРОЙСТВАМ В СОСТАВЕ НИЗКОЭМИССИОННОЙ СИСТЕМЫ СЖИГАНИЯ КУЗНЕЦКОГО УГЛЯ
}

\author{
Копань Александр Владимирович1, \\ alexander.kopan@zio-cotes.ru \\ Клейнерман Владимир Алексеевич2, \\ vladimir.kleinerman@ennova.energy \\ 1 O०० «ЗиО-КОТЭС», \\ Россия, 630049, г. Новосибирск, ул. Кропоткина, 96/1. \\ 2 AO «ЭHHOBA», \\ Россия, 630049, г. Новосибирск, ул. Кропоткина, 96/1.
}

В статье рассматриваются мероприятия, направленные на снижение экологически вредных выбросов оксидов азота при сжигании кузнецких углей марки Д на энергетических котлах типа E-240-13,8-560КТ (заводское обозначение ПК-114) применительно к строящейся тепловой электростанции в Калининградской области.

Целью исследования является разработка комплекса технических мероприятий для внедрения на вновь вводимьх в работу энергетических котлах по горелочным устройствам, топкам котлов и системам пылеприготовления, способствующих не только низкоэмиссионному сжиганию кузнецких углей марки Д, но и обеспечивающих требуемые технико-экономические показатели.

Объектом исследования являются топочные процессы, горелочные устройства энергетических котлов и системы пылеприготовления.

Методом исследования является математическое моделирование топочных процессов.

Актуальность данной работы обусловлена важностью обеспечения соответствия экологическим нормам, в частности нормам выбросов оксидов азота NOx, вновь вводимого в работу энергетического оборудования.

Рассмотренные в статье технические мероприятия выбраны по результатам численного моделирования топочного процесса и расчета таких его параметров, как поля температур, концентраця дискретной фазы и содержание кислорода на различных высотных отметках и сечениях при варьируемых исходных данных (включая расположение сопл третичного дутья, перераспределение воздуха по горелкам и т. д.).

Итогом исследования явился обоснованный выбор одного из них в качестве рабочего варианта.

\section{Ключевые слова:}

Энергетический котел, оксиды азота, низкоэмиссионное сжигание третичное дутье, горизонтальная стадийность сжигания, ПК-114.

\section{Введение}

В соответствии с проектом в рамках обеспечения энергетической безопасности Калининградской области осуществлено строительство новой угольной электростанции. Реализация проекта позволит диверсифицировать топливный баланс Калининградской энергосистемы.

Основными требованиями для выбора энергетического оборудования являлись обеспечение надежности при работе, а также соответствие современным экологическим нормам. Проблемы, связанные с соответствием экологическим нормам, расцениваются экспертами как те, на которые должна быть направлена государственная политика [1]. В связи с этим стоит отметить, что природоохранная проблематика наряду с разработкой сверхмощных угольных энергоблоков с высокой эффективностью являются инициативами, которые поддерживаются Международным энергетическим агентством для восполнения недостатка финансирования в области традиционной энергетики [2]. Кроме того, согласно новому природоохранному законодательству, резко увеличиваются платежи за превышение технологических нормативов за загрязнение окружающей среды, которые будут соизмеримы с затратами на внедрение наилучших доступных технологий, что предоставляет дополнительный стимул для соблюдения экологических норм [3].

В связи с вышеизложенным проектные технические решения для котлов номинальной паропроизводительностью 240 т/ч с параметрами перегретого пара $560{ }^{\circ} \mathrm{C}$ и 13,8 МПа ориентированы на достижение выбросов оксидов азота $\mathrm{NO}_{x}$ не более $450 \mathrm{мг} / \mathrm{Hм}^{3}$ и потерь от механического недожога топлива менее 1,0\%. Данное целеполагание требует предваряющих вариативных исследований процессов сжигания топлива с учетом его фракционных характеристик в зависимости от возможных сочетаний взаимной компоновки устройств ввода и диапазона расходов воздушных потоков, а также их направленности.

\section{Объект и методы исследования}

Объектом исследования с целью выбора оптимальных вариантов для принципиальных решений по организации сжигания топлива при реализации проекта котла явилась топочная камера, схема которой приведена на рис. 1.

Заданным проектным топливом определен каменный уголь марки Д Кузнецкого бассейна (добываемый 
на Задубровском и Виноградовском угольных разрезах). Опорным решением для разработки схемы пылесжигания явился выбор систем пылеприготовления с молотковыми мельницами типа ММТ 1500/2750/750К, обеспечивающими тонину помола по остатку на сите 90 мкм $R_{90}=15 \ldots 20 \%$. Схема пылесжигания, предполагающая комплексное воздействие на генерацию оксидов азота, включает в себя компоновку горелочных устройств из трех разнесенных по высоте топки ярусов основных горелок и одного яруса сопл третичного дутья (рис. 1). Предполагалось, что удачная реализация этой схемы позволит достичь снижения концентрации $\mathrm{NO}_{\mathrm{x}}$ в дымовых глазах на $30 \ldots 40 \%$ [4]. Такой эффект возможен благодаря тому, что сгорание летучих веществ происходит в обедненной кислородом среде, и азотсодержащие компоненты летучих (цианиды и амины) переходят главным образом не в соединения $\mathrm{NO}_{\mathrm{x}}$, а в безвредный инертный молекулярный азот $\mathrm{N}_{2}$ [5].
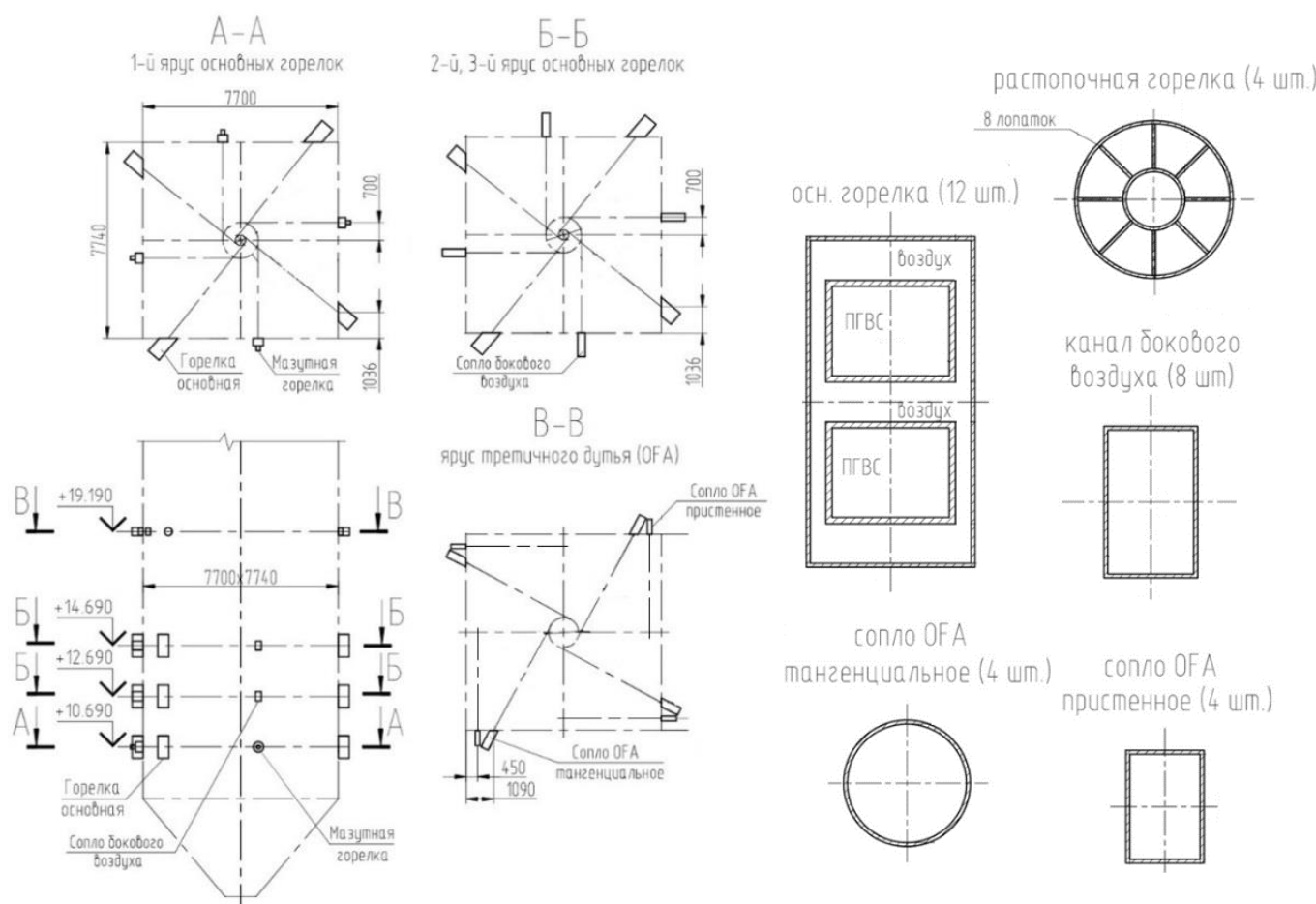

Pис. 1. Конструктивная схема топочной камеры исследуемого котла

Fig. 1. Structural diagram of the test combustion chamber of the boiler

Для организации устойчивого сжигания топлива в топке рассматриваемого энергетического котла с требуемыми показателями были проведены серии многовариантых расчетов топочных процессов при различных компоновках топочно-горелочных устройств. При этом в каждой серии исследовалось влияние отдельного фактора для нескольких схем различной конфигурации на неизменных или незначительно изменяемых других факторах. Вариации технических решений включали в себя: расположение сопл третичного дутья; перераспределение вторичного воздуха между спутными каналами основных горелок и боковыми каналами; местоположение горелок одного яруса вдоль стен топочной камеры и каждого яруса по высоте топки; диапазон тонкости помола угольной пыли.

Расчетные исследования выполнены в программном комплексе Ansys Fluent.

\section{Результаты исследований}

Поскольку для обеспечения эффективного сжигания топлива необходима реализация взаимодействия топливных струй, струй вторичного и третичного воздуха в топочном пространстве [6], в качестве ключевого было выбрано такое расположение сопл тре- тичного дутья, в котором пристенный и тангенциальные яруса третичного дутья объединены в один ярус на промежуточной отметке, отстоящей на 4,5 м от третьего яруса горелок [7]. Такое решение позволило обеспечить более полное и равномерное перекрытие кислородом сечения топочной камеры, что подтверждают картины визуализации параметров топочной среды, приведенные на рис. 2-7. Результирующим эффектом явилось лучшее выгорание топлива, подтверждаемое приведенными в таблице интегральными показателями [8] для двух крайних значений исследованного диапазона тонкости помола угольной пыли: механический недожог $q_{4}$ составляет $0,40 \ldots 0,75 \%$, при этом концентрация $\mathrm{NO}_{x}$ не превышает допустимых значений.

Расчеты по данному варианту выполнялись на различные тонкости помола угольной пыли $\left(R_{90}=15 \%\right.$ и $R_{90}=20 \%$ при сохранении коэффициента полидисперсности $n=1,18$ :

- для варианта с тонкостью помола угольной пыли $R_{90}=15 \%\left(R_{200}=0,75 \%\right)$ концентрация оксидов азота NOx составляет 419 мг/нм ${ }^{3}$, а потери с механической неполнотой сгорания $q_{4}-0,58 \%$, температура на выходе из топки $T^{\prime \prime}{ }_{\mathrm{T}}-1082{ }^{\circ} \mathrm{C}$; 
- д для варианта с тонкостью помола угольной пыли $R_{90}=20 \%\left(R_{200}=1,6 \%\right)$ концентрация оксидов азота NOx составляет 446 мг/нм ${ }^{3}$, а потери с механической неполнотой сгорания $q_{4}-0,75 \%$, температура на выходе из топки $T^{\prime \prime}{ }_{\mathrm{T}}-1075^{\circ} \mathrm{C}$. a)

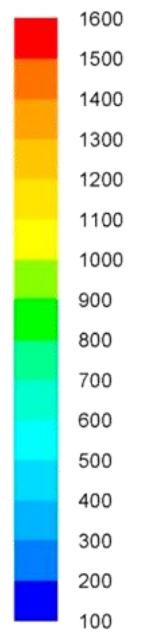

б)

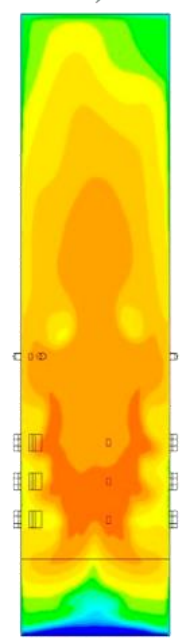

Pис. 2. Поле температур в осевых сечениях, ${ }^{\circ} \mathrm{C}$ : а) по продольной оси; б) по поперечной оси

Fig. 2. Field of temperatures at axial sections, ${ }^{\circ} \mathrm{C}:$ a) along the longitudinal axis; $b$ ) along the transverse axis
Видно, что подобное уменьшение тонкости помола увеличивает в $\sim 1,3$ раза итоговое значение механического недожога и на 6-9 \% концентрацию оксидов азота. a)

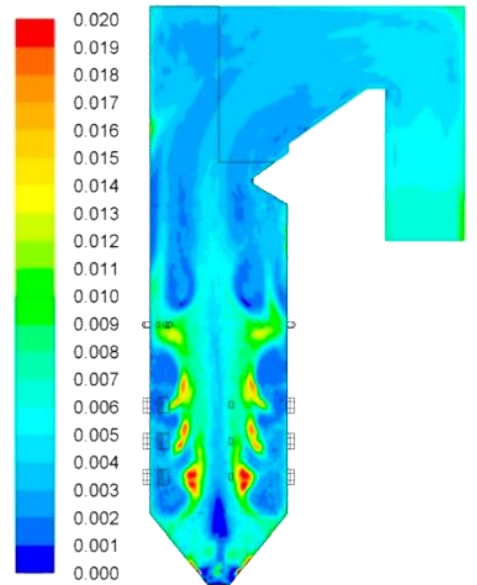

б)

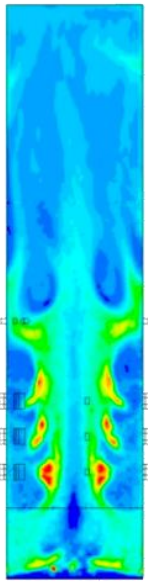

Рис. 4. Поле кониентраиии дискретной фазы в осевых

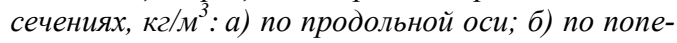
речной оси

Fig. 4. Field of discrete phase concentration at the axial sections, $\mathrm{kg} / \mathrm{m}^{3}$ : a) along the longitudinal axis; b) along the transverse axis a)

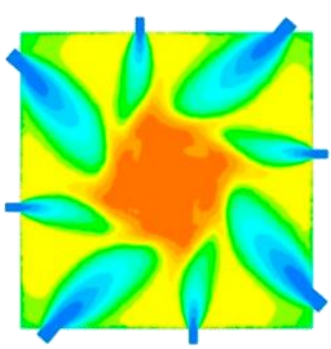

б)

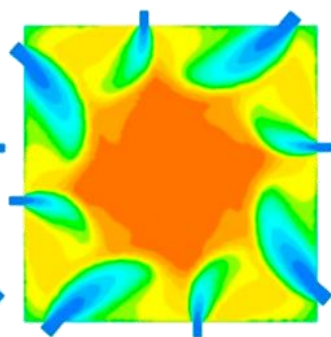

B)

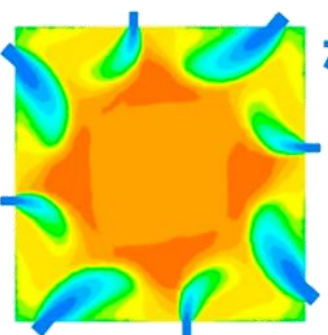

г)

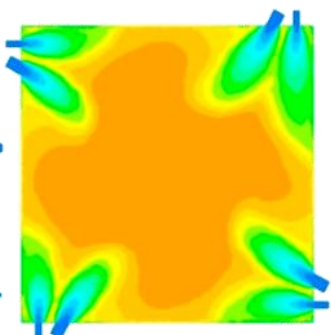

Рис. 3. Поле температур в горизонтальных сечениях поярусно, ${ }^{\circ} \mathrm{C}$, на отметке: а) $+10,690$; б) +12,690; в) +14,690; 2) $+19,190 \mathrm{M}$

Fig. 3. Field of temperatures at the different altitude heights, ${ }^{\circ} \mathrm{C}$, at the level of: a) $\left.\left.+10,690 ; b\right)+12,690 ; c\right)+14,690$; d) $+19,190 m$

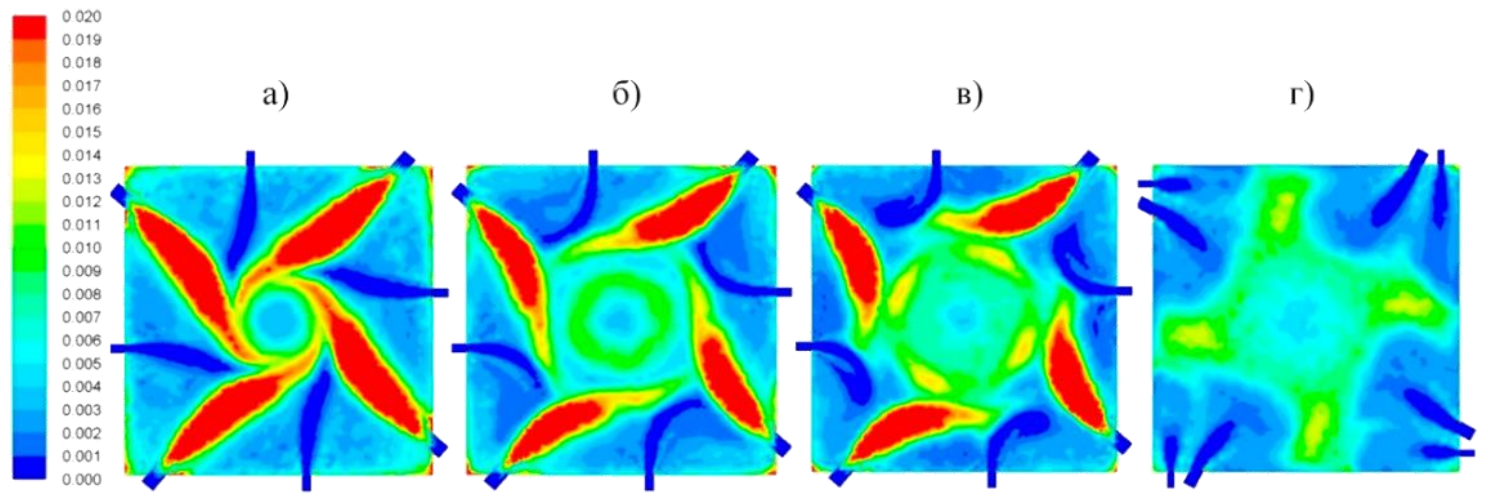

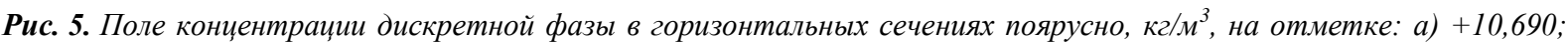
б) $+12,690$; в) $+14,690$; г) $+19,190 \mathrm{M}$

Fig. 5. Field of discrete phase concentration at the burners altitude heights, $\mathrm{kg} / \mathrm{m}^{3}$, at the level of: a) $\left.+10,690 ; b\right)+12,690$; c) $+14,690 ; d)+19,190 m$ 


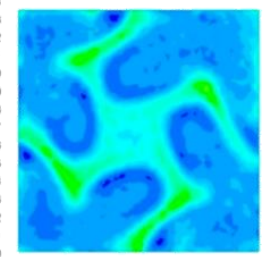

б)

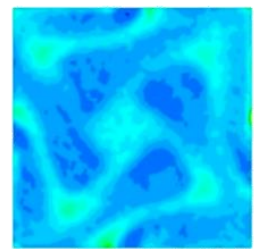

в)

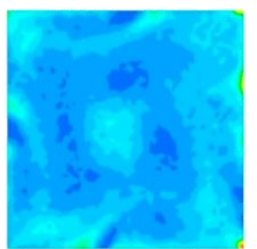

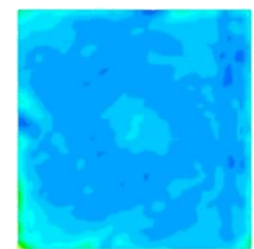

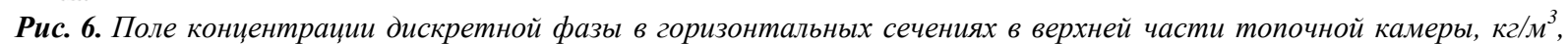
на отметке: a) $+21,000$; б) +23,000; в) $+25,000$; г) $+28,000 \mathrm{M}$

Fig. 6. Field of discrete phase concentration at the altitude heights, $\mathrm{kg} / \mathrm{m}^{3}$, at the level of: a) $\left.+21,000 ; b\right)+23,000$; c) $+25,000 ; d)+28,000 m$

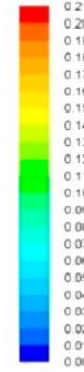

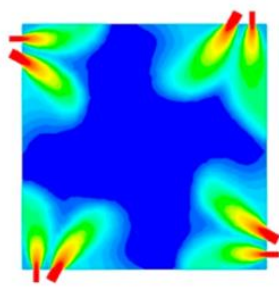

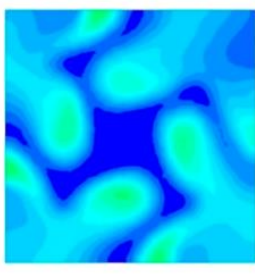

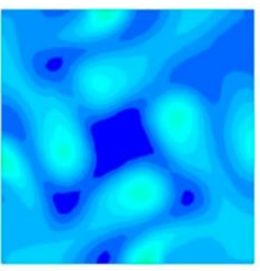

г)

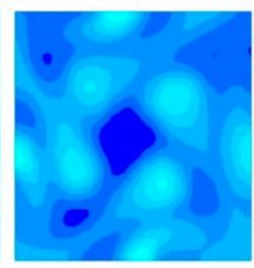

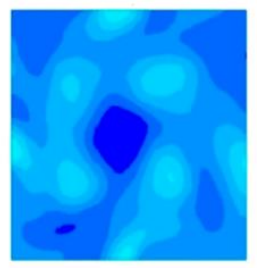

Рис. 7. Поле концентрации кислорода в горизонтальных сечениях в верхней части топочной камеры, \%/100, на отметке: а) $+19,900 ;$ б) $+21,000$; в) $+23,000$; г) $+25,000$; d) $+28,000 \mathrm{M}$

Fig. 7. Field of oxygen concentration at the altitude heights, $\% / 100$, at the level of: a) $+19,900 ; b)+21,000 ; c)+23,000$; d) $+25,000 ; e)+28,000 m$

По результатам исследований схема сжигания была оптимизирована для дополнительного снижения выбросов оксидов азота [9]. Известно, что сжигание топлив с малыми избытками воздуха без значительных выбросов возможно только при усовершенствовании горелочных устройств, позволяющем интенсифицировать процесс горения [10]. Для этого был рассмотрен перенос части вторичного воздуха (5 \% от общего вторичного воздуха) из каналов основных горелок в боковые сопла. Таким образом, избыток воздуха на основных горелках был уменьшен с 0,63 до 0,59.

Чтобы влияние перераспределения воздуха было более показательным, расчеты по этому варианту проводились на угрубленный помол угольной пыли $R_{90}=20 \% ; R_{200}=1,6 \%$.

По результатам расчетов:

1) доля первичного воздуха от $\mathrm{BV}_{0}$ составляет 0,052 ;

2) доля вторичного воздуха в спутные каналы основных горелок от $\mathrm{BV}_{0}$ составляет 0,538 (0,65 от общего вторичного воздуха);

3) доля вторичного воздуха в боковые сопла от $\mathrm{BV}_{0}$ coставляет 0,29 (0,35 от общего вторичного воздуха);

4) доля третичного воздуха в ярус сопл OFA от $\mathrm{BV}_{0}$ составляет 0,25 ;

5) присосы в топку составляют 0,02 ;

6) избыток воздуха на выходе из топки составляет 1,15 .

По результатам расчетов при номинальной паропроизводительности котла и принятой тонкости помола угольной пыли концентрация оксидов азота $\mathrm{NO}_{\mathrm{x}}$ составляет $436 \mathrm{мг} / \mathrm{Hм}^{3}$, потери с механической неполнотой сгорания $q_{4}-0,68 \%$, а температура на выходе из топки $T^{\prime}{ }_{\mathrm{T}}-1082{ }^{\circ} \mathrm{C}$.
Соответственно, можно сделать вывод, что перераспределение дополнительного количества вторичного воздуха $\left(4,2 \%\right.$ от $\left.\mathrm{BV}_{0}\right)$ в боковые каналы горелок позволяет снизить итоговую концентрацию оксидов азота на $20 \mathrm{мг} / \mathrm{Hм}^{3}$. При этом незначительно уменьшилось расчетное значение механического недожога $q_{4}$ (с 0,75 до $0,68 \%$ ).

Полученный вариант с расположением топочногорелочных устройств удовлетворял требуемым показателям и был принят как основной для проекта.

Для проверки влияния работы пылеприготовительного оборудования на показатели топочного процесса вариант 1 был просчитан на разные тонкости помола угольной пыли: $R_{90}=15 \% ; R_{90}=20 \%$ и $R_{90}=30 \%$ (при сохранении коэффициента полидисперсности $n=1,18)$. Результаты расчетов для $100 \%$ нагрузки котла трехмельничного режима на задубровском угле приведены в таблице.

Из таблицы видно, что требуемые параметры по концентрации оксидов азота $\left(\mathrm{NO}_{\mathrm{x}} \leq 450 \mathrm{M \Gamma} / \mathrm{Hм}^{3}\right)$ и уровню выгорания топлива $\left(q_{4} \leq 1 \%\right)$ возможны при подержании тонкости помола угольной пыли $R_{90}=15 \ldots 20 \%$. Вместе с тем данные результаты говорят о целесообразности приближения к минимально возможной тонкости помола на уровне $R_{90}=15 \%$ $[11,12]$.

Итоговые решения по топочно-горелочным устройствам включают установку мазутных горелок вместо боковых сопл 1-го яруса, что на этапе исследований топочных процессов было принято как упрощение и не учитывалось [13]. 
Таблица. Влияние тонкости помола угольной пыли на расчетные показатели топочного процесса

Table. Influence of grinding fineness on the calculated rates of the combustion process

\begin{tabular}{|c|c|c|c|}
\hline Показатель/Rate & \multicolumn{3}{|c|}{ Значение/Amount } \\
\hline $\begin{array}{l}\text { Тонкость помола угольной } \\
\text { пыли } \\
\text { Fineness of coal dust grinding }\end{array}$ & $\begin{array}{c}R_{90}=15 \% \\
R_{200}=0,75 \%\end{array}$ & $\begin{array}{r}R_{90}=20 \% \\
R_{200}=1,6 \%\end{array}$ & $\begin{array}{r}R_{90}=30 \% \\
R_{200}=4,5 \%\end{array}$ \\
\hline Нагрузка котла/Boiler load, \% & \multicolumn{3}{|c|}{100} \\
\hline $\begin{array}{l}\text { Паропроизводительность } \\
\text { котла, т/ч } \\
\text { Boiler steam capacity, t/h }\end{array}$ & \multicolumn{3}{|c|}{240} \\
\hline $\begin{array}{l}\text { Количество работающих } \\
\text { мельниц } \\
\text { Number of working mills }\end{array}$ & \multicolumn{3}{|c|}{3} \\
\hline Тип топлива/Fuel type & \multicolumn{3}{|c|}{ Задубровский уголь/Zadubrovsky coal } \\
\hline $\begin{array}{l}\text { Концентрация } \mathrm{NO}_{\mathrm{x}}, \mathrm{Mг} / \mathrm{Hм}^{3} \\
\mathrm{NO}_{\mathrm{x}} \text { concentration, } \mathrm{mg} / \mathrm{nm}^{3}\end{array}$ & 406 & 433 & 499 \\
\hline $\begin{array}{l}\text { Потери с механической не- } \\
\text { полнотой сгорания* } q_{4}, \% \\
\text { Losses with the mechanical in- } \\
\text { completeness of burning*, } q_{4}, \%\end{array}$ & 0,58 & 0,78 & 1,58 \\
\hline $\begin{array}{l}\text { Потери } \mathrm{q}_{4} \text { с «провалом», \% } \\
\mathrm{q}_{4} \text { losses with «collapse», \% }\end{array}$ & 0,07 & 0,13 & 0,37 \\
\hline $\begin{array}{l}\text { Температура на выходе } \\
\text { из топки } T^{\prime *} * *_{\mathrm{r}},{ }^{\circ} \mathrm{C} \\
\text { Temperature at the exit } \\
\text { of the furnace } T^{\prime \prime} *,{ }^{\circ} \mathrm{C}\end{array}$ & 1081 & 1079 & 1063 \\
\hline
\end{tabular}

* - за ширмами/за котлом; **-в сечении перед иирмами.

* - behind the screens/the boiler; ** - in the section before the screens.

\section{Использование результатов}

Проведенные исследования способствовали выработке заводом-изготовителем окончательных проектных решений по конструктивному оформлению топки котла и в целом схемы пылесжигания.

Топка имеет в плане по осям труб размеры $7700 \times 7740$ мм с соотношением сторон, которое оптимально подходит для реализации тангенциальной схемы сжигания. Она способствует эффективному перемешиванию топочной среды и постоянному притоку горячих топочных газов к устью горелок, обеспечивая надежное воспламенение угольной пыли. Приток обедненных кислородом топочных газов к струе аэросмеси, выходящей из горелки, создает условия для снижения генерации оксидов азота $[13,14]$.

В качестве основных горелочных устройств приняты прямоточные горелки, состоящие из двух каналов пылегазовоздушной смеси. Количество основных горелок 12. Горелки расположены в три яруса (отм. $+10,690,+12,690$ и +14,690 м) на фронтовой, задней и боковых стенах топочной камеры, их оси направлены по касательным к условным окружностям. Сечения каналов основных горелок выбраны из условий обеспечения требуемых выходных скоростей на номинальной нагрузке (бо́льшие значения для двухмельничного режима): аэросмеси $W_{1}=14,6 \ldots 18,1 \mathrm{~m} / \mathrm{c}$ и вторичного воздуха $W_{2}=24$ м/с. Боковые сопла 2-го и 3-го ярусов имеют прямоугольную форму. Сечения боковых сопел выбраны из условия обеспечения выходной скорости вторичного воздуха $\sim 24 \mathrm{~m} / \mathrm{c}$ на номинальной нагрузке. Боковые сопла первого яруса выполнены в виде кольцевых каналов с лопаточным завихрителем, в которые встроены 4 мазутные фор- сунки. За счет этого при пуске котла данные устройства выполняют функции мазутных растопочных горелок, а в номинальном пылеугольном режиме - сопл бокового воздуха.

Расположение горелок в нескольких разнесенных по высоте топки ярусах позволяет осуществлять так называемую вертикальную ступенчатость сжигания. Ступенчатая подача топлива позволяет дополнительно уменьшить максимальные температуры в топке, что снижает образование термических $\mathrm{NO}_{\mathrm{x}}$ [15]. Четыре из восьми сопл третичного дутья выполняются в виде пристенного дутья в «противокрутку» основному потоку для дожигания частиц топлива, отбрасываемых за счет вращательного движения факела к стенам и в углы топочной камеры, а также для защиты экранов от высокотемпературной коррозии в восстановительной среде [16]. Остальные четыре сопла устанавливаются по тангенциальной схеме также с «противокруткой» основному вращению топочных газов, что обеспечивает лучшее смешивание воздуха с пылегазовой средой и более полное выгорание топлива [17]. В сумме на ярус третичного дутья подается $25 \%$ от теоретически необходимого для сжигания воздуха.

Наличие ярусов также позволяет производить поярусное подключение горелок к мельницам, в результате чего отключение одной мельницы не приводит к сколько-нибудь значимым изменениям в аэродинамике топки [18].

Для снижения избытка воздуха на основных горелках часть воздуха (в объеме $29 \%$ от теоретически необходимого количества на номинальной нагрузке) подается в 12 боковых сопл, расположенных на уровне ярусов основных горелок. Кроме поддержания вращательной способности факела при различных режимах это создает защиту экранов топки от коррозии за счет исключения восстановительной атмосферы вблизи экранов в области активного горения [19] и реализует в каждом ярусе горизонтальную стадийность сжигания угольной пыли, которая также является действенным способом уменьшения образования оксидов азота [20, 21].

В качестве мероприятия, повышающего устойчивость процессов горения при задействовании всех вышеназванных технических решений во время работы котла на сниженных нагрузках, проектом предусмотрена глубокая сушка угольной пыли дымовыми газами [22].

\section{Заключение}

Средствами компьютерного моделирования пакета программ Ansys Fluent по результатам многовариантных численных исследований параметров процесса горения было выбрано оптимальное сочетание технических решений по топочно-горелочным устройствам. Выбранная схема сжигания легла в основу проекта котла ПК-114 Подольского машиностроительного завода. В Калининградской области завершаются строительные работы Приморской ТЭС, где установлены котлы ПК-114 для блоков 65 МВт. 


\section{СПИСОК ЛИТЕРАТУРЫ}

1. Форсайт-исследование технологии угольной генерации энергии / В.И. Суслов, Н.В. Горбачева, А.В. Кузнецов, Н.О. Фурсенко // Всероссийский экономический журнал ЭКО. - 2011. № 4. - C. $60-71$.

2. Горбачева Н.В. Динамика инновационной деятельности традиционной и возобновляемой энергетики. Сравнительный анализ // Инновации. - 2019. - № 5. - С. 35-45.

3. Повышение экологической безопасности, надежности и экономичности пылеугольных котлов / Э.П. Волков, А.М. Архипов, В.Б. Прохоров, С.Л. Чернов // Проблемы региональной энергетики. - 2017. - № 1. - С. 45-52.

4. Бурима Л.Я. Экологическая безопасность энергетического сектора как необходимое условие устойчивого развития // Вестник Прикамского социального института. - 2018. - № 1. C. $72-83$.

5. Практика и перспективы применения различных способов сжигания твердого топлива в теплоэнергетических установках М.Н. Башкова, С.А. Казимиров, М.В. Темплянцев, В.И. Багрянцев, А.А. Рыбушкин, К.С. Слажнева // Вестник Сибирского государственного индустриального университета. - 2014. № 2. - С. 24-31.

6. Исследования на физической и математической моделях аэродинамики топки котла при применении вихревой схемы сжигания твердого топлива / В.Б. Прохоров, С.Л. Чернов В.С. Киричков, А.А. Каверин // Проблемы региональной энергетики. - 2018. - № 1. - С. 1-11.

7. Effects of OFA ratio on coal combustion and NOx generation of 600-MW downfired boiler after changing air distribution around fuel-rich flow / Zeng Lingyuan, Li Xiaoguang, Zhang Shaofeng, Pei Jiangtao, Song Minhang, Chen Zhichao, Wang Liang, Wang Jiaquan, Li Zhengqi // Journal of Energy Engineering. - 2019. № 1. - P. 125-139.

8. Архипов А.М., Путилов В.Я. Влияние максимально быстрого прогрева и зажигания пыли кузнецких углей на комплексную эффективность работы энергетических котлов // Теплоэнергетика. - 2010. - № 6. - С. 12-19.

9. Hodzic N., Kazaganic A., Metovic S. Influence of over fire air system on NOx emissions: An experimental case study // Thermal Science. - 2019. - № 3. - P. 2037-2045.

10. Вагнер А.А. Комплексное повышение эффективности ступенчатого сжигания кузнецкого угля на котле с тангенциально направленными горелками и твердым шлакоудалением // Электрические станции. - 2004. - № 10. - С. 38-43.
11. Жуйков А.В., Матюшенко А.И. Снижение оксидов азота в процессе сжигания канско-ачинских углей // Журнал Сибирского федерального университета. Техника и технологии. 2014. - № 5. - C. 596-604.

12. Yu Li, Weidong Fan. Experimental research of the NOx evolvement of pulverized coal combusted in $\mathrm{CO} 2$, Ar and N2 atmospheres // Energy Conversion and Management. - 2015. - № 106. P. 457-465.

13. Архипов А.М., Путилов В.Я. Ступенчатое факельное сжигание кузнецких углей на ТЭС // Теплоэнергетика. - 2009. № 8. - C. 104-109.

14. Осинцев К.В. Расчетная модель топочного устройства с различными компоновками горелочных устройств // Вестник Южно-Уральского государственного университета. Серия: Энергетика. - 2014. - № 3. - С. 5-14.

15. Двойнишников В.А., Хохлов Д.А. Влияние способа ввода газов рециркуляции на конфигурации амбразуры вихревой горелки на горение газового топлива и образование оксидов азота в факеле // Теплоэнергетика. - 2017. - № 5. - С. 56-65.

16. Котлер В.Р. Защита топочных экранов от шлакования // Энергохозяйство за рубежом. - 2019. - № 1. - С. 19-21.

17. Menn N., Chudnovsky B. New technology for monitoring fouling deposition in coal fired boilers VGB // PowerTech. - 2016. № 6. - P. 65-70.

18. Тринченко А.А. Снижение выбросов оксидов азота при ступенчатом сжигании топлива // Научно-технические ведомости СПбГУ. Естественные и инженерные науки. - 2011. - № 2. C. $104-109$.

19. Costa M., Azevedo J.L.T. Experimental characterization of an industrial pulverized coal-fired furnace under deep staging conditions // Combustion Science and Technology. - 2007. - № 7. - P. 1923-1935.

20. Cao H., Sun S. Computational fluid dynamics modeling of NOx reduction mechanism in oxi-fuel combustion // Energy Fuels. 2010. - № 24. - P. 131-135.

21. Alvarez L., Charebagh M., Jones J.M. Numerical investigation of NO emissions from an entrained flow reactor under oxycoal conditions // Fuel Process. Technol. - 2012. - № 93. - P. 53-64.

22. Lun Ma., Qingyan Fang, Chungen Yin. A novel corner-fired boiler system of improved efficiency and coal flexibility and reduced NOx emissions // Applied Energy. - 2019. - № 238. - P. 453-465.

Поступила 19.11.2020 2.

\section{Информация об авторах}

Kопань A.B., ведущий инженер пуско-наладочного отдела ООО «ЗиО-КОТЭС».

Клейнерман В.A., старший инженер отдела наладки и испытаний АО «ЭННОВА». 
UDC 621.18-182.2

\title{
TESTING TECHNICAL SOLUTIONS FOR THE BURNER DEVICES AS A LOW-EMISSION SYSTEM OF KUZNETSK COAL COMBUSTION
}

\author{
Aleksandr V. Kopan ${ }^{1}$, \\ alexander.kopan@zio-cotes.ru \\ Vladimir A. Kleinerman², \\ vladimir.kleinerman@ennova.energy \\ 1 «ZiO-KOTES» Ltd, \\ 96/1, Kropotkin street, Novosibirsk, 630049, Russia. \\ 2 JSC «ENNOVA», \\ 96/1 Kropotkin street, Novosibirsk, 630049 Russia.
}

The paper considers the solutions regarding decreasing of environmentally harmful nitrogen oxide emissions when combusting the Kuznetsk coal grade D on the power boilers of E-240-13,8-560KT type for the newly built power plant in Kaliningrad oblast.

The aim of the research is to develop the list of technical solutions that will be implemented on the newly built power boilers for the burner devices, furnaces and the dust preparation system, which will contribute to low-emission combustion of Kuznetsk coal grade $D$ and will provide the needed technical and economical results.

The object of the study is furnace processes, burner devices of power boilers and the dust preparation systems.

The research method is mathematical modeling of combustion processes.

The relevance of this article is caused by the importance of compliance of newly built power equipment with the environmental standards, in particular the standards of nitrogen oxide emissions.

The following solutions were chosen after mathematical modeling of combustion process and calculation of such parameters as the field of temperatures, concentrations of discrete phase and oxygen at the different altitude heights and sections with different initial data (like the positioning of overfire air nozzles, air redistribution).

The result of the study was a reasonable choice of the only working option.

\section{Key word:}

Boiler, nitrogen oxides, low emission combustion, overfire air, horizontally staged combustion, PK-114.

\section{REFERENCES}

1. Suslov V.I., Gorbacheva N.V., Kuznetsov A.V., Fursenko N.O. Forsayt-issledovanie tekhnologii ugolnoy generatsii energii [Foresight study of coal energy generation technology]. Vserossiyskiy ekonomicheskiy zhurnal EKO, 2011, no. 4, pp. 60-71.

2. Gorbacheva N.V. Dinamika innovatsionnoy deyatelnosti traditsionnoy i vozobnovlyaemoy energetiki. Sravnitelny analiz [Dynamics of innovation activities of traditional and renewable energy. Comparative analysis]. Innovatsii, 2019, no. 5, pp. 35-45.

3. Volkov E.P., Arkhipov A.M., Prokhorov V.B., Chernov S.L. Povyshenie ekologicheskoy bezopasnosti, nadezhnosti i ekonomichnosti pyleugolnykh kotlov [Increase of ecological safety, reliability and efficiency of coal-fired boilers]. Problemy regionalnoy energetiki, 2017, no. 1, pp. 45-52.

4. Burima L.Ya. Ecological safety of the energy sector as necessary condition of sustainable development. Bulletin of Prikamsky Social Institute, 2018, no. 1, pp. 72-83. In Rus.

5. Bashkova M.N., Kazimirov S.A., Templyantsev M.V., Bagryantsev V.I., Rybushkin A.A., Slazhneva K.S. Praktika i perspektivy primeneniya razlichnykh sposobov szhiganiya tverdogo topliva $\mathrm{v}$ teploenergeticheskikh ustanovkakh [Practice and prospects for application of various methods of solid fuel combustion in thermal power plants]. Vestnik Sibirskogo gosudarstvennogo industrial'nogo universiteta, 2014, no. 2, pp. 24-31.

6. Prokhorov V.B., Chernov S.L., Kirichkov V.S., Kaverin A.A. Issledovaniya na fizicheskoy i matematicheskoy modelyakh aerodinamiki topki kotla pri primenenii vikhrevoy skhemy szhiganiya tverdogo topliva [Research on physical and mathematical models of the boiler furnace aerodynamics when using a vortex scheme of solid fuel combustion]. Problemy regionalnoy energetiki, 2018, no. 1, pp. 1-11.

7. Zeng Lingyuan, Li Xiaoguang, Zhang Shaofeng, Pei Jiangtao, Song Minhang, Chen Zhichao, Wang Liang, Wang Jiaquan, Li Zhengqi. Effects of OFA ratio on coal combustion and NOx generation of a $600-\mathrm{MW}$ downfired boiler after changing air dis- tribution around fuel-rich flow. Journal of Energy Engineering, 2019, no. 1, pp. 125-139.

8. Arkhipov A.M., Putilov V.Ya. Vliyanie maksimalno bystrogo progreva i zazhiganiya pyli kuzneckikh ugley na kompleksnuyu effektivnost raboty energeticheskikh kotlov [Influence of the fastest possible heating and ignition of Kuznetsk coal dust on the complex efficiency of power boilers]. Teploenergetika, 2010, no. 6, pp. 12-19.

9. Hodzic N., Kazaganic A., Metovic S. Influence of over fire air system on NOx emissions: An experimental case study. Thermal Science, 2019, no. 3, pp. 2037-2045.

10. Vagner A.A. Kompleksnoe povyshenie effektivnosti stupenchatogo szhiganiya kuznetskogo uglya na kotle s tangentsialno napravlennymi gorelkami i tverdym shlakoudaleniem [Comprehensive increase in the efficiency of staged combustion of Kuznetsk coal in a boiler with tangentially directed burners and solid ash removal]. Elektricheskie stantsii, 2004, no. 10, pp. 38-43.

11. Zhuykov A.V., Matyushenko A.I. Snizhenie oksidov azota v protsesse szhiganiya kansko-achinskikh ugley [Decrease of nitrogen oxides in the combustion process Kansk-Achinsk Coal]. Journal of Siberian Federal University. Engineering \& Technologies, 2014, no. 5, pp. 596-604

12. $\mathrm{Yu} \mathrm{Li}$, Weidong Fan. Experimental research of the NOx evolvement of pulverized coal combusted in $\mathrm{CO} 2, \mathrm{Ar}$ and $\mathrm{N} 2$ atmospheres. Energy Conversion and Management, 2015, no. 106, pp. $457-465$.

13. Arkhipov A.M., Putilov V.Ya. Stupenchatoe fakelnoe szhiganie kuznetskikh ugley na TES [Staged flare combustion of Kuznetsk coal at TPP]. Teploenergetika, 2009, no. 8, pp. 104-109.

14. Osinesev K.V. Computational model of furnace unit with various layouts of burners. Bullent of the South Ural State University Series «Power Engineering», 2014, no. 3, pp. 5-14. In Rus.

15. Dvoynishnikov V.A., Khokhlov D.A. Vliyanie sposoba vvoda gazov retsirkulyatsii na konfiguratsii ambrazury vikhrevoy gorelki na gorenie gazovogo topliva i obrazovanie oksidov azota $\mathrm{v}$ fakele [Influence of the method for introducing recirculation gases on the configuration of the vortex burner opening on the combustion of 
gas fuel and the formation of nitrogen oxides in the flame]. Teploenergetika, 2017, no. 5, pp. 56-65.

16. Kotler V.R. Zashchita topochnykh ekranov ot shlakovaniya [Protection of furnace walls from slagging]. Energohozyaystvo za rubezhom, 2019, no. 1, pp. 19-21.

17. Menn N., Chudnovsky B. New technology for monitoring fouling deposition in coal fired boilers VGB. PowerTech, 2016, no. 6, pp. 65-70.

18. Trinchenko A.A. Snizhenie vybrosov oksidov azota pri stupenchatom szhiganii topliva [Reducing nitrogen oxide emissions from staged fuel combustion]. Nauchno-tekhnicheskie vedomosti SPbGU. Estestvennye i inzhenernye nauki, 2011, no. 2, pp. 104-109.

19. Costa M., Azevedo J.L.T. Experimental characterization of an industrial pulverized coal-fired furnace under deep staging conditions Combustion Science and Technology, 2007, no. 7, pp. 1923-1935.
20. Cao H., Sun S. Computational fluid dynamics modeling of NOx reduction mechanism in oxi-fuel combustion. Energy Fuels, 2010, no. 24, pp. 131-135.

21. Alvarez L., Charebagh M., Jones J.M. Numerical investigation of $\mathrm{NO}$ emissions from an entrained flow reactor under oxycoal conditions. Fuel Process. Technol, 2012, no. 93, pp. 53-64.

22. Lun Ma., Qingyan Fang, Chungen Yin. A novel corner-fired boiler system of improved efficiency and coal flexibility and reduced NOx emissions. Applied Energy, 2019, no. 238, pp. 453-465.

Received: 19 November 2020.

\section{Information about the authors}

Aleksandr V. Kopan, leading engineer, «ZiO-KOTES» Ltd; assistant, National Research Tomsk Polytechnic University. Vladimir A. Kleinerman, senior engineer, JSC «ENNOVA». 